\title{
Experimental lung injury induces cerebral cytokine mRNA production in pigs
}

\author{
Jens Kamuf ${ }^{\text {Corresp., } 1}{ }^{\text {, Andreas Garcia Bardon }}{ }^{1}$, Alexander Ziebart ${ }^{1}$, Katrin Frauenknecht ${ }^{2}$, Konstantin Folkert ${ }^{1}$, \\ Johannes Schwab $^{1}$, Robert Ruemmler ${ }^{1}$, Miriam Renz $^{1}$, Denis Cana ${ }^{2}$, Serge C Thal ${ }^{1}$, Erik K Hartmann ${ }^{1}$ \\ 1 Department of Anesthesiology, Medical Centre of the Johannes Gutenberg-University, Mainz, Germany \\ 2 Institute of Neuropathology, Medical Centre of the Johannes Gutenberg-University, Mainz, Germany \\ Corresponding Author: Jens Kamuf \\ Email address: kamuf@uni-mainz.de
}

Background. Acute respiratory distress syndrome (ARDS) is an important disease with a high incidence among patients admitted to intensive care units. Over the last decades, the survival of critically ill patients has improved; however, cognitive deficits are among the long-term sequelae. We hypothesize that acute lung injury leads to upregulation of cerebral cytokine synthesis.

Methods. After approval of the institutional and animal care committee, 20 male pigs were randomized to one of three groups. 1. Lung injury by oleic acid injection (OAI), 2. ventilation only (CTR) or 3. untreated. We compared neuronal numbers, proportion of neurons with markers for apoptosis, activation state of Iba-1 stained microglia cells and cerebral mRNA levels of different cytokines between the groups 18 hours after onset of lung injury.

Results. We found an increase in hippocampal TNFalpha $(p<0.05)$ and IL-6 $(p<0.05)$ messenger RNA (mRNA) in the OAl compared to untreated group as well as higher hippocampal IL-6 mRNA compared to control $(p<0.05)$. IL-8 and IL-1beta mRNA showed no differences between the groups. We found histologic markers for beginning apoptosis in OAl compared to untreated $(p<0.05)$ and more active microglia cells in OAI and CTR compared to untreated ( $p<0.001$ each).

Conclusion. Hippocampal cytokine transcription increases within 18 hours after the induction of acute lung injury with histological evidence of neuronal damage. It remains to be elucidated, if increased cytokine mRNA synthesis plays a role in the cognitive decline observed in survivors of ARDS. 


\section{Experimental lung injury induces cerebral cytokine mRNA}

\section{2 production in pigs}

3

4 Jens Kamuf ${ }^{1}$, Andreas Garcia Bardon ${ }^{2}$, Alexander Ziebart ${ }^{3}$, Katrin Frauenknecht ${ }^{4}$, 5 Konstantin Folkert ${ }^{5}$, Johannes Schwab ${ }^{6}$, Robert Rümmler ${ }^{7}$, Miriam Renz ${ }^{8}$, Denis Cana, 6 Serge $\mathbf{C}$ Thal ${ }^{10}$ and Erik K Hartmann ${ }^{11}$

$7 \quad{ }^{1}$ Department of Anesthesiology, University Medical Centre, Mainz

$8 \quad{ }^{2}$ Department of Anesthesiology, University Medical Centre, Mainz

$9 \quad{ }^{3}$ Department of Anesthesiology, University Medical Centre, Mainz

$10{ }^{4}$ Institute of Neuropathology, University Medical Centre, Mainz

$11 \quad{ }^{5}$ Department of Anesthesiology, University Medical Centre, Mainz

$12{ }^{6}$ Department of Anesthesiology, University Medical Centre, Mainz

$13{ }^{7}$ Department of Anesthesiology, University Medical Centre, Mainz

$14{ }^{8}$ Department of Anesthesiology, University Medical Centre, Mainz

$15{ }^{9}$ Institute of Neuropathology, University Medical Centre, Mainz

$16{ }^{10}$ Department of Anesthesiology, University Medical Centre, Mainz

19 Corresponding Author:

20 Jens Kamuf

21 Langenbeckstr. 1, Mainz, Rheinland-Pfalz, 55131, Mainz

22 Email address: kamuf@uni-mainz.de

23 
25 Abstract

26 Background. Acute respiratory distress syndrome (ARDS) is an important disease with a high

27 incidence among patients admitted to intensive care units. Over the last decades, the survival of

28 critically ill patients has improved; however, cognitive deficits are among the long-term

29 sequelae. We hypothesize that acute lung injury leads to upregulation of cerebral cytokine 30 synthesis.

31 Methods. After the institutional and animal care committee approved this study, 20 male pigs

32 were randomized to one of three groups. 1. Lung injury by oleic acid injection (OAI), 2.

33 ventilation only (CTR) or 3. untreated. We compared neuronal numbers, proportion of neurons

34 with markers for apoptosis, activation state of Iba-1 stained microglia cells and cerebral mRNA

35 levels of different cytokines between the groups 18 hours after onset of lung injury.

36 Results. We found an increase in hippocampal TNFalpha $(\mathrm{p}<0.05)$ and IL-6 $(\mathrm{p}<0.05)$ messenger

37 RNA (mRNA) in the OAI compared to untreated group as well as higher hippocampal IL-6

38 mRNA compared to control $(\mathrm{p}<0.05)$. There was no intergroup difference regarding IL-8 or IL-

39 1beta mRNA.. We found histologic markers for beginning apoptosis in OAI compared to

40 untreated $(\mathrm{p}<0.05)$ and more active microglia cells in OAI and CTR compared to untreated

$41 \quad(\mathrm{p}<0.001$ each $)$.

42 Conclusion. Hippocampal cytokine transcription increases within 18 hours after the induction of

43 acute lung injury with histological evidence of neuronal damage. It remains to be elucidated, if

44 increased cytokine mRNA synthesis plays a role in the cognitive decline observed in survivors of 45 ARDS. 


\section{Introduction}

49

50 The management of patients with acute respiratory distress syndrome (ARDS) has substantially

51 improved over the years(Rezoagli et al. 2017). However, the late effects of critical care as well

52 as health-related quality of life issues are emerging as a significant challenge for ARDS

53 survivors (Herridge 2017). These patients demonstrate an impaired quality of live and a decline

54 in cognitive function even one year after hospital discharge (Hopkins et al. 2005; Mikkelsen et

55 al. 2012). The cognitive impairment encompasses global cognition and executive function

56 (Pandharipande et al. 2013), approaching cognition scores similar to those seen in patients with

57 moderate traumatic brain injury or Alzheimer's disease (Herridge et al. 2016).

58 The underlying pathophysiological mechanisms are poorly understood, but are likely complex

59 and multifactorial. Global hypoxia (Kandikattu et al. 2017), inflammation (Dantzer et al. 2008),

60 oxidative stress (Popa-Wagner et al. 2013), and autonomic nervous system dysregulation

61 (Gonzalez-Lopez et al. 2013) constitute proposed mechanisms. Of note, even mechanical

62 ventilation alone leads to hippocampal apoptosis and could contribute to the cognitive decline

63 (Gonzalez-Lopez et al. 2013).

64 In an earlier study, we examined neuronal injury and inflammation six hours after onset of

65 ARDS in a porcine model (Kamuf et al. 2018a). We found an increase in cerebral cytokine

66 expression in mechanically ventilated pigs that was independent of additional lung injury

67 compared to untreated animals. We concluded that six hours of ventilation may not be enough

68 time for a profound cerebral effect, so we aimed to extend the duration of ARDS. We

69 hypothesize that acute lung injury leads to an upregulation of cerebral cytokine production and

70 neuronal degeneration despite lung protective ventilation and that this effect is partly transferred 
71 via serum cytokines. The present study therefore compares cerebral mRNA concentrations of

72 different cytokines to neuronal numbers at 18 hours after onset of ARDS in a porcine model. 


\section{Materials \& Methods}

74

75 The institutional and state animal care committee approved this prospective randomized animal

76 study (Landesuntersuchungsamt Rheinland-Pfalz, Koblenz, Germany; approval number G14-1-

77 077), which was conducted in accordance with international guidelines for the care and use of

78 laboratory animals. The animals used in this study were also part of another study that has not

79 yet been published (approved under the same approval number), the untreated animals served as

80 untreated control animals in a previously published study (Kamuf et al. 2018a). All animals were

81 housed, fed and euthanized equally. This manuscript adheres to EQUATOR guidelines.

82

\section{Anaesthesia and Instrumentation}

84 Twenty healthy male pigs (sus scrofa domesticus, weight: $26-33 \mathrm{~kg}$ ) were randomized to one of

85 three groups: lung injury by central venous injection of oleic acid (OAI, n=8), ventilation only

$86(\mathrm{CTR}, \mathrm{n}=8)$, or untreated animals $(\mathrm{n}=4)$. After a local breeder delivered the sedated animals

87 (ketamine $4 \mathrm{mg} \mathrm{kg}^{-1}$, azaperon $8 \mathrm{mg} \mathrm{kg}^{-1}$ intramuscularly), we establishedan intravenous line.

88 Then, anesthesia was induced and maintained by propofol (8-12 $\left.\mathrm{mg} \mathrm{kg}^{-1} \mathrm{~h}^{-1}\right)$ and fentanyl (0.1-

$\left.890.2 \mathrm{mg} \mathrm{kg}^{-1} \mathrm{~h}^{-1}\right) .0 .5 \mathrm{mg} \mathrm{kg}^{-1}$ atracurium was administered to facilitate orotracheal intubation. The

90 Respirator (Engström Carestation ${ }^{\circledR}$, GE Healthcare, Germany) was started in pressure-controlled

91 mode with the following settings: tidal volume $\left(\mathrm{V}_{\mathrm{t}}\right)$ of $7 \mathrm{ml} \mathrm{kg}-1$, PEEP of $5 \mathrm{cmH}_{2} \mathrm{O}$, fraction of

92 inspired oxygen $\left(\mathrm{FiO}_{2}\right)$ of 0.4 and a variable respiratory rate to maintain normocapnia. At this

93 point, the animals of the untreated group were sacrificed in deep anesthesia with a central venous

94 injection of $200 \mathrm{mg}$ propofol and $40 \mathrm{mmol}$ potassium. In all other animals, a balanced electrolyte

95 solution (Sterofundin iso, B. Braun, Germany) was continuously infused at a rate of $5 \mathrm{ml} \mathrm{kg}^{-1} \mathrm{~h}^{-1}$.

96 Vascular catheters were placed ultrasound-guided: an arterial line, a pulse contour cardiac output 
97 catheter (PiCCO, Pulsion Medical Systems, Germany), a central venous line and a 7.5-French

98 introducer for a pulmonary arterial catheter were inserted via femoral vascular access.

99 Respiratory and extended hemodynamic parameters were recorded continuously (Datex S/5, GE

100 Healthcare, Germany). Further respiratory parameters and measurements were recorded by the 101 respirator. Normothermia was maintained by body surface warming.

102

103 Study protocol

104 Following instrumentation, we set the $\mathrm{F}_{\mathrm{i}} \mathrm{O}_{2}$ to 1.0 and conducted a lung recruitment maneuver 105 (plateau pressure $40 \mathrm{cmH}_{2} \mathrm{O}$ for 10 seconds). Then, baseline, premorbid parameters were 106 assessed. Lung injury was induced as previously published(Kamuf et al. 2018b). $0.1 \mathrm{ml} \mathrm{kg}^{-1} \mathrm{of}$

107 oleic acid (cis-9-octadecenoic acid) was dissolved in $20 \mathrm{ml}$ of a saline/blood mixture and injected 108 every three minutes via the central venous line in fractions of $2 \mathrm{ml}$. The procedure was repeated 109 with another $0.1 \mathrm{ml} \mathrm{kg}^{-1}$ after 15 minutes, if the $\mathrm{PaO}_{2} / \mathrm{FiO}_{2}$ was higher than $200 \mathrm{mmHg}$. After 110 ARDS criteria were fulfilled, the animals were treated according to a standard protocol, which 111 was closely adapted to human ICU treatment as previously published(Kamuf et al. 2018b).

112 Respirator settings are as follows: $V_{\mathrm{t}} 7 \mathrm{ml} \mathrm{kg}^{-1}, \mathrm{FiO}_{2}$ and PEEP according to table 1, with an 113 intended peripheral oxygen saturation of $94-98 \%$. Norepinephrine was administered as needed 114 to maintain stable hemodynamic conditions during the experiments (mean arterial pressure $>65$ $115 \mathrm{mmHg}$ ). 18 hours after manifestation of the lung injury, the animals were killed by injecting 200 $116 \mathrm{mg}$ propofol and $40 \mathrm{mmol}$ potassium. 


\section{Post-mortem Analysis}

118 For post-mortem analysis we removed the brain and lungs of the animals after they died. The

119 brain was sectioned in the midsagittal plane, one half was fixed in $4 \%$ formaldehyde solution for

1203 months, a slice of the frontal cortex and hippocampus were removed from the other hemisphere

121 (Klein et al. 2016). Both samples were snap frozen (in liquid nitrogen) for molecular biological

122 analysis. Lung was used for wet/dry ratio (Kamuf et al. 2017) and histopathology (Hartmann et

123 al. 2014).

124 Initially, the hippocampus was cut in $2 \mathrm{~mm}$ thick slices. Four tissue slices were then sectioned

125 through the entire specimen and embedded in paraffin. Subsequently, additional $4 \mu \mathrm{m}$ thick

126 histological sections were prepared. Preparations were stained with hematoxylin/eosin (HE) and

127 examined with light microscopy to assess the number of HE-stained neurons (Songarj et al.

128 2015) (see supplemental figures 1-6 for representative pictures). Furthermore, we quantified the

129 proportion of damaged neurons, whereby eosinophilic degeneration and nuclear pyknosis were

130 defined as markers for early neuronal damage. To distinguish between different activation states

131 of the microglia, slices were stained with an antibody against Iba-1 (WAKO, Japan). Iba-1

132 positive cell numbers / $\mathrm{mm} 2$ were counted in one visual field $\left(380 \mathrm{~mm}^{2}\right)$. We further

133 differentiated between microglia without branches, defined as activated, and microglia with three

134 or more branches, defined as resting. Microglia with one or two branches were defined as in-

135 between.

136

137 Dependent and non-dependent lung regions were sampled, fixed in formalin for paraffin

138 sectioning and stained with HE. Then we applied a lung injury score according to earlier

139 publications (Ziebart et al. 2014). The evaluation included seven different parameters: 
140 overdistension, epithelial destruction, inflammatory infiltration, alveolar edema, hemorrhage,

141 interstitial edema, and microatelectasis. Per region, each parameter received a severity grade

142 from zero to five points in four non-overlapping fields of view. In a second step, the extent of

143 each parameter was assessed in a global overview of the entire region. This approach results in

144 an overall score of 175 maximum points per region.

145 To determine cerebral messenger RNA (mRNA) expression of TNFalpha, IL-6, IL-8 and IL-

146 1beta, we used real-time polymerase chain reaction (RT-PCR, Lightcycler 480 PCR System,

147 Roche Applied Science, Germany) (Hartmann et al. 2015). mRNA expression data were

148 normalized against peptidylprolyl isomerase A (PPIA) as control gene.

149 After ARDS-induction, 6, 12 and 18 hours later, blood samples were taken via the cental venous

150 catheter and snap frozen for determination of cytokine levels (IL-6 and TNFalpha) using ELISA

151 kits (Porcine IL-6 Quantikine ELISA, Porcine TNFalpha Quantikine ELISA, R\&D Systems,

152 Wiesbaden, Germany) according to the instructions of the manufacturer.

153

154 Statistics

155 Statistical analyses were performed by One-way ANOVA with post-hoc tests for multiple testing

156 (SNK-Test), except for the analyses of the physiologic data. These were analyzed by Two-way

157 Repeated Measures ANOVA with post-hoc correction (SNK-Test). The results were analyzed

158 and graphed using Sigmaplot ${ }^{\circledR}$ 12.5. A $\mathrm{p}<0.05$ was considered significant.

159

160

161

162

163

164

165 
166

167

168

169

170

171

172

173

174

175

176

177

178

179

180 181

182

183

184

185

186

187

188

189

\section{Results}

Induction of lung injury led to a significant decrease in oxygenation ratio and an increase in peak pressure $\left(\mathrm{P}_{\text {peak }}\right)$ at all measured time points compared to control animals (CTR). Furthermore, in animals with lung injury induced by central venous injection of oleic acid (OAI), positive endexpiratory pressure (PEEP), inspiratory fraction of $\mathrm{O} 2\left(\mathrm{FiO}_{2}\right)$ and extravascular lungwater index (EVLWI) were significantly higher at selected timepoints compared to CTR. Tidal volume $\left(\mathrm{V}_{\mathrm{T}}\right)$, end-expiratory $\mathrm{CO}_{2}$ and wet-to-dry ratio showed no difference between the groups.

Heart rate and mean pulmonary arterial pressure (MPAP) were significantly increased in OAI compared to CTR at all measured time points after induction of lung injury. Central venous pressure (CVP), pulmonary capillary wedge pressure (PCWP), cardiac index and norepinephrine dose differed at some time points. Mean arterial pressure (MAP) showed no difference between the groups. Cardiopulmonary characteristics of the animals are provided in tables 2 and 3 and in supplemental tables 1 and 2 .

There was no difference in the number of neurons $(p=0.69$; fig. 1$)$ in the hippocampus (pooled data of Gyrus Dentatus, CA1, CA2, CA3 and CA4) between the groups. Histologic evaluation of neuronal damage showed a significantly higher proportion of damaged neurons in the

hippocampus of OAI animals compared with untreated animals ( $p=0.02$; pooled data of Gyrus Dentatus, CA1, CA3 and CA4). However, there was no difference between OAI and CTR $(p=0.11)$ or between CTR and untreated ( $p=0.16$; fig. 1$)$.

The number of Iba-1 stained microglia cells in the hippocampus didn't differ between the groups $(p=0.71$; fig. 2 ), but evaluation of their activation state by counting the number of branches 
190 revealed significantly more active microglia cells in OAI and CTR compared to untreated

$191(\mathrm{p}<0.001$ each), while there was no significant difference between OAI and CTR ( $\mathrm{p}=0.12 ;$ fig. 2$)$.

192 Comparison of resting microglia cells, defined as microglia cells with three or more branches,

193 showed significantly fewer resting microglia cells in OAI compared to untreated $(\mathrm{p}=0.006)$ and

194 in CTR compared to untreated $(\mathrm{p}=0.007)$. There was no difference between OAI and CTR

$195(p=0.53)$.

196

197 Lung injury was pronounced in the OAI group ( $p=0.01$ versus CTR, $p<0.001$ versus untreated).

198 The lungs of the CTR animals showed a significant higher damage score than the untreated $199 \operatorname{group}(\mathrm{p}=0.04$; fig. 3).

200

201 We found no difference in mRNA concentrations of TNFalpha $(p=0.31$; fig. 4), IL-6 ( $p=0.062$;

202 fig. 5), IL-8 ( $p=0.68$; fig. 6) or IL-1beta ( $p=0.43$; fig. 7) in the cortex samples. The hippocampus 203 showed a significant increase of TNFalpha mRNA in OAI $(p=0.005)$ and CTR $(p=0.004)$

204 animals compared to untreated animals. There was no difference between the CTR and OAI 205 group ( $\mathrm{p}=0.67$; fig. 4). IL-6 mRNA was significantly increased in the hippocampus of the 206 animals of the OAI group compared to CTR $(p=0.02)$ and untreated $(p=0.049)$. There was no 207 significant difference between CTR and untreated ( $p=0.62 ;$ fig. 5). Hippocampal IL-8 ( $p=0.18$; 208 fig. 6) and IL-1beta ( $p=0.58$; fig. 7) mRNA copies showed no differences between the groups. 209

210 Plasma IL-6 levels in OAI animals were significantly higher after 18 hours compared to 12 hours $211(\mathrm{p}=0.03)$ and compared to 6 hours $(\mathrm{p}=0.03$; fig. 8). Plasma IL-6 levels in CTR animals showed 212 no significant difference over time $(\mathrm{p}=0.35)$. Plasma TNFalpha levels were significantly higher 
213 after ARDS-induction in OAI animals compared to 6 hours $(\mathrm{p}=0.02), 12$ hours $(\mathrm{p}=0.02)$ and 18

214 hours ( $\mathrm{p}=0.01$; fig. 8). There was no significant change in Plasma TNFalpha in CTR animals

215 over time $(\mathrm{p}=0.68)$.

216 


\section{Discussion}

218 In this study, we found an increase in cerebral cytokine mRNA without histological evidence of 219 neuronal damage after OAI-induced lung injury, already within 24 hours.

220 Central venous injection of oleic acid is an established animal model of acute lung injury, which

221 is characterized by alveolar hemorrhage, intravascular thrombosis, infiltration of

222 polymorphonuclear leukocytes, and increased pulmonary microvascular permeability. These

223 changes lead to severe ventilation/perfusion mismatch and increased shunt resulting in

224 hypoxemia and increased mean airway pressures. Furthermore, pulmonary edema develops,

225 which is characterized by elevation of extravascular lung water and leakage of protein-rich fluid

226 into the airspace and interstitium. Commonly observed hemodynamic effects encompass

227 myocardial depression, early systemic hypotension, and pulmonary hypertension (Matute-Bello

228 et al. 2008), which have been reliably reproduced in our porcine model. In our study, gas

229 exchange and pulmonary arterial hypertension resolved over time in contrast to Derks et al., who

230 reported a maximum effect after 12 hours (Derks \& Jacobovitz-Derks 1977). This discrepancy

231 may be attributable to continuous lung protective ventilation, which may minimize alveolar

232 stress as well as cyclic recruitment and derecruitment (Nieman et al. 2015), thereby impeding the

233 inflammatory response.

234 IL-6 and TNFalpha are important mediators in the development of ARDS (Goncalves-de-

235 Albuquerque et al. 2015). An increase in serum IL-6 is associated with the development of 236 ARDS (Aisiku et al. 2016) and elevated intracranial pressure (Hergenroeder et al. 2010) in

237 patients with traumatic brain injury. An increase in these cytokines is also associated with 238 postoperative delirium and cognitive dysfunction (Wang et al. 2015). Therefore, we examined 239 systemic levels of IL-6 in the OAI animals immediately after ARDS-induction and found a 
240 significant increase, which diminished over time. In OAI animals, only a trend towards higher

241 levels of TNFalpha was observed. This finding is concordant with an animal study on acid

242 aspiration induced lung injury over 5 days, which reported a similar TNF-alpha temporal

243 evolution with a tendency to an increase in serum IL-6 (Bickenbach et al. 2011).

244 Circulating TNFalpha can compromise the blood brain barrier (Tsao et al. 2001) and activate

245 microglia cells. Importantly, circulating IL-6 is thought to impair the blood brain barrier likewise

246 (Rochfort \& Cummins 2015). Furthermore, TNFalpha can activate microglia cells through

247 receptors within the cerebral blood vessels (Thibeault et al. 2001). To examine a potential

248 activation of microglia, we assessed the number of iba-1 stained microglia cells, but found no

249 difference between the groups. However, the homogenous distribution of microglia in our

250 present study does not necessarily rule out microglia activation since microglia with similar

251 appearance can exhibit different functional phenotypes, dependent on their microenvironment

252 (Wes et al. 2016). Hence, we examined different activation states of microglia cells by counting

253 their branch numbers. Significantly more active microglia cells in OAI and CTR compared to

254 untreated $(\mathrm{p}<0.001$ each) was paralleled by significantly fewer resting cells in OAI and CTR

255 compared to untreated (OAI vs. untreated $p=0.006$; CTR vs. untreated $p=0.007$ ). In septic mice

256 an activation of microglia is usually found after 8-48 hours (Hoogland et al. 2015). Sepsis leads

257 to rapid breakdown of the blood brain barrier causing cerebral inflammation (Danielski et al.

258 2018), but Cytokine release in ARDS is not as pronounced as in sepsis (Ziebart et al. 2014).

259 Accordingly, the breakdown - or potential breakdown - of the blood brain barrier may take

260 longer, which could explain our results. Furthermore, activation of microglial cells is not

261 necessarily accompanied by an increase in numbers. Additional evidence of microglial activation

262 is the cerebral production of TNFalpha or IL-6 mRNA, since these cytokines are mainly released 
263 by microglia cells (Hoogland et al. 2015) and a hippocampal increase in these cytokines is 264 associated with postoperative cognitive decline (Chen et al. 2015). In animals of the OAI group 265 hippocampal IL-6 mRNA was significantly increased compared to untreated and CTR animals. 266 This confirms the results of Bellaver et al., who examined cerebral cytokine production in 267 animals with cecal ligation and perforation. They found an increase in hippocampal IL-6 268 production (Bellaver et al. 2018). Hippocampal TNFalpha mRNA showed a non-significant 269 tendency towards higher level in OAI compared to untreated, but not between OAI and CTR.

270 This finding differs from the results reported by Ruiz-Valdepenas et al., who found a significant 271 increase in cerebral TNFalpha mRNA after lipopoylsaccharide-induced sepsis (Ruiz-Valdepenas 272 et al. 2011).

273 In the next step, cerebral injury was assessed by evaluating neuronal counts in the hippocampus.

274 However, we found no difference between the groups. In contrast, Gonzales-Lopez et al. 275 described initial signs of neuronal apoptosis in mechanically ventilated mice after only 90 276 minutes of non-protective ventilation (Gonzalez-Lopez et al. 2013). Heuer et al. reported a non277 significant tendency towards more severe hippocampal injury within four hours in pigs with 278 acid-aspiration induced lung damage (Heuer et al. 2012). In another porcine two-hit model of 279 acid-aspiration and non-protective ventilation, no signs for hippocampal apoptosis were found 280 (Bickenbach et al. 2011). These discrepancies could be explained by the fact, that we counted 281 HE-stained neurons, without differentiation in the morphology of the cells, whereas Heuer et al. 282 evaluated nuclear pyknosis and eosinophilic degeneration of the cytoplasm as markers of 283 neuronal cell damage. Bickenbach et al. used similar criteria, whereas Gonzales-Lopes 284 considered PARP-1 positive neurons as evidence of injury. Hence, we evaluated the proportion 285 of neurons with nuclear pyknosis or hypereosinophilia as markers for acute neuronal damage. 
286 We found significantly more eosinophilic and pyknotic neurons in the hippocampus of OAI

287 animals compared to untreated animals whereas the overall number of neurons in the

288 hippocampus remained unchanged.

289

290 There are several limitations of our study. Lung injury induced by injection of oleic acid is a

291 well-established model for acute ARDS characterized by a profound change in oxygenation due

292 to microvascular thrombosis, leucocyte infiltration, necrosis and leakage of protein-rich fluid

293 into the airspace with extravascular lung water accumulation (Goncalves-de-Albuquerque et al.

294 2015). Our model showed oxygenation impairment and extravascular lung water accumulation,

295 which improved during the course of the study. The wet-to-dry ratio, as a marker for pulmonary

296 edema did not differ between the lung injury group and the control group. This indicates an

297 improvement of the lung injury, possibly due to the lung-protective ventilator setting. Gonzales-

298 Lopez et al. found significant apoptosis in the hippocampus of mice that were non-protectively

299 ventilated, even without ARDS (Gonzalez-Lopez et al. 2013). They showed that this

300 hippocampal damage was mediated by the vagal nerve, which is activated by stretch sensors in

301 the lungs (Gourine et al. 2008). Our lung-protective ventilation may have prevented vagal nerve

302 mediated hippocampal damage by reducing distension on the lungs. Furthermore, the observed

303 improvement of lung injury markers could correspond to reduced lung inflammation. This could

304 lead to an attenuated cytokine release in the blood with less pronounced systemic inflammatory

305 response and accordingly reduced cerebral inflammation and apoptosis, compared to septic

306 conditions, which lead to hippocampal damage (Semmler et al. 2005) and long-term memory

307 deficits (Semmler et al. 2007). Another limitation is the duration of our experiment. Usually

308 patients with ARDS require mechanical ventilation for several days (Bellani et al. 2016), 
309 whereas our experiment was limited to 18 hours. This may be too short to induce a profound

310 cerebral response that is not mediated by the nervous system itself, but by the circulatory system.

311 The systemic immune response usually lacks some days after localized infection. Finally, we

312 only examined mRNA of the cerebral cytokines, not proteins. The increase of mRNA is not

313 necessarily followed by an increase in protein concentration. Accordingly, our results should be

314 interpreted with caution.

315

\section{Conclusions}

317 Hippocampal cytokine mRNA increases within 18 hours after induction of acute lung injury 318 without histological evidence of neuronal loss. Furthermore, we found an increase in serum 319 cytokines after induction of lung injury. Although we did not evaluate cognitive function after 320 acute lung injury, prior studies have documented that an increase in hippocampal IL-6 and 321 TNFalpha result in cognitive dysfunction. Therefore, it is plausible that an increase in cytokine 322 mRNA may contribute to cognitive decline in the setting of ARDS, especially if it is followed by 323 an increase in cerebral cytokine synthesis. Further studies should investigate the temporal 324 evolution of cytokine elevation and its influence on cognitive dysfunction. 


\section{Acknowledgements}

327 We thank Dagmar Dirvonskis and Dana Pieter for excellent technical support. The authors are

328 grateful to Prof. Elisabeth Jane Rushing (University Hospital Zurich, Switzerland) for critically 329 reading the manuscript. This work contains parts of the medical thesis of KoFo and JS. 
335

336

337

338

339

340

341

342

343

344

345

346

347

348

349

350

351

352

353

354

355

356

357

358

359

360

361

362

363

364

365

366

367

368

369

370

371

372

373

374

375

376

377

378

379

380

381

382

383

\section{References}

Aisiku IP, Yamal JM, Doshi P, Benoit JS, Gopinath S, Goodman JC, and Robertson CS. 2016. Plasma cytokines IL-6, IL-8, and IL-10 are associated with the development of acute respiratory distress syndrome in patients with severe traumatic brain injury. Crit Care 20:288. 10.1186/s13054-016-1470-7

Bellani G, Laffey JG, Pham T, Fan E, Brochard L, Esteban A, Gattinoni L, van Haren F, Larsson A, McAuley DF, Ranieri M, Rubenfeld G, Thompson BT, Wrigge H, Slutsky AS, Pesenti A, Investigators LS, and Group ET. 2016. Epidemiology, Patterns of Care, and Mortality for Patients With Acute Respiratory Distress Syndrome in Intensive Care Units in 50 Countries. JAMA 315:788-800. 10.1001/jama.2016.0291

Bellaver B, Dos Santos JP, Leffa DT, Bobermin LD, Roppa PHA, da Silva Torres IL, Goncalves CA, Souza DO, and Quincozes-Santos A. 2018. Systemic Inflammation as a Driver of Brain Injury: the Astrocyte as an Emerging Player. Mol Neurobiol 55:2685-2695. 10.1007/s12035-017-0526-2

Bickenbach J, Biener I, Czaplik M, Nolte K, Dembinski R, Marx G, Rossaint R, and Fries M. 2011. Neurological outcome after experimental lung injury. Respir Physiol Neurobiol 179:174-180. 10.1016/j.resp.2011.08.003

Chen C, Zhang Z, Chen T, Peng M, Xu X, and Wang Y. 2015. Prolonged mechanical ventilation-induced neuroinflammation affects postoperative memory dysfunction in surgical mice. Crit Care 19:159. 10.1186/s13054-015-0882-0

Danielski LG, Giustina AD, Badawy M, Barichello T, Quevedo J, Dal-Pizzol F, and Petronilho F. 2018. Brain Barrier Breakdown as a Cause and Consequence of Neuroinflammation in Sepsis. Mol Neurobiol 55:1045-1053. 10.1007/s12035-016-0356-7

Dantzer R, O'Connor JC, Freund GG, Johnson RW, and Kelley KW. 2008. From inflammation to sickness and depression: when the immune system subjugates the brain. Nat Rev Neurosci 9:46-56. 10.1038/nrn2297

Derks CM, and Jacobovitz-Derks D. 1977. Embolic pneumopathy induced by oleic acid. A systematic morphologic study. Am J Pathol 87:143-158.

Goncalves-de-Albuquerque CF, Silva AR, Burth P, Castro-Faria MV, and Castro-Faria-Neto HC. 2015. Acute Respiratory Distress Syndrome: Role of Oleic Acid-Triggered Lung Injury and Inflammation. Mediators Inflamm 2015:260465. 10.1155/2015/260465

Gonzalez-Lopez A, Lopez-Alonso I, Aguirre A, Amado-Rodriguez L, Batalla-Solis E, Astudillo A, Tomas-Zapico C, Fueyo A, dos Santos CC, Talbot K, and Albaiceta GM. 2013. Mechanical ventilation triggers hippocampal apoptosis by vagal and dopaminergic pathways. Am J Respir Crit Care Med 188:693-702. 10.1164/rccm.201304-0691OC

Gourine AV, Dale N, Korsak A, Llaudet E, Tian F, Huckstepp R, and Spyer KM. 2008. Release of ATP and glutamate in the nucleus tractus solitarii mediate pulmonary stretch receptor (Breuer-Hering) reflex pathway. J Physiol 586:3963-3978. 10.1113/jphysiol.2008.154567

Hartmann EK, Thomas R, Liu T, Stefaniak J, Ziebart A, Duenges B, Eckle D, Markstaller K, and David M. 2014. TIP peptide inhalation in experimental acute lung injury: effect of repetitive dosage and different synthetic variants. BMC Anesthesiol 14:42. 10.1186/1471-2253-14-42

Hartmann EK, Ziebart A, Thomas R, Liu T, Schad A, Tews M, Moosmann B, Kamuf J, Duenges B, Thal SC, and David M. 2015. Inhalation therapy with the synthetic TIP-like peptide AP318 attenuates pulmonary inflammation in a porcine sepsis model. BMC Pulm Med 15:7. 10.1186/s12890-015-0002-6

Hergenroeder GW, Moore AN, McCoy JP, Jr., Samsel L, Ward NH, 3rd, Clifton GL, and Dash PK. 2010. Serum IL-6: a candidate biomarker for intracranial pressure elevation 
384

385

386

387

388

389

390

391

392

393

394

395

396

397

398

399

400

401

402

403

404

405

406

407

408

409

410

411

412

413

414

415

416

417

418

419

420

421

422

423

424

425

426

427

428

429

430

431

432

433

434

following isolated traumatic brain injury. J Neuroinflammation 7:19. 10.1186/1742-20947-19

Herridge MS. 2017. Fifty Years of Research in ARDS. Long-Term Follow-up after Acute Respiratory Distress Syndrome. Insights for Managing Medical Complexity after Critical Illness. Am J Respir Crit Care Med 196:1380-1384. 10.1164/rccm.201704-0815ED

Herridge MS, Moss M, Hough CL, Hopkins RO, Rice TW, Bienvenu OJ, and Azoulay E. 2016. Recovery and outcomes after the acute respiratory distress syndrome (ARDS) in patients and their family caregivers. Intensive Care Med 42:725-738. 10.1007/s00134016-4321-8

Heuer JF, Sauter P, Pelosi P, Herrmann P, Bruck W, Perske C, Schondube F, Crozier TA, Bleckmann A, Beissbarth T, and Quintel M. 2012. Effects of pulmonary acid aspiration on the lungs and extra-pulmonary organs: a randomized study in pigs. Crit Care 16:R35. $10.1186 / \mathrm{cc} 11214$

Hoogland IC, Houbolt C, van Westerloo DJ, van Gool WA, and van de Beek D. 2015. Systemic inflammation and microglial activation: systematic review of animal experiments. $J$ Neuroinflammation 12:114. 10.1186/s12974-015-0332-6

Hopkins RO, Weaver LK, Collingridge D, Parkinson RB, Chan KJ, and Orme JF, Jr. 2005. Twoyear cognitive, emotional, and quality-of-life outcomes in acute respiratory distress syndrome. Am J Respir Crit Care Med 171:340-347. 10.1164/rccm.200406-7630C

Kamuf J, Garcia-Bardon A, Duenges B, Liu T, Jahn-Eimermacher A, Heid F, David M, and Hartmann EK. 2017. Endexpiratory lung volume measurement correlates with the ventilation/perfusion mismatch in lung injured pigs. Respir Res 18:101. 10.1186/s12931017-0585-y

Kamuf J, Garcia-Bardon A, Ziebart A, Thomas R, Folkert K, Frauenknecht K, Thal SC, and Hartmann EK. 2018a. Lung injury does not aggravate mechanical ventilation-induced early cerebral inflammation or apoptosis in an animal model. PLoS One 13:e0202131. 10.1371/journal.pone.0202131

Kamuf J, Garcia-Bardon A, Ziebart A, Thomas R, Rummler R, Mollmann C, and Hartmann EK. 2018b. Oleic Acid-Injection in Pigs As a Model for Acute Respiratory Distress Syndrome. $J$ Vis Exp. 10.3791/57783

Kandikattu HK, Deep SN, Razack S, Amruta N, Prasad D, and Khanum F. 2017. Hypoxia induced cognitive impairment modulating activity of Cyperus rotundus. Physiol Behav 175:56-65. 10.1016/j.physbeh.2017.03.035

Klein KU, Johannes A, Bruckner M, Thomas R, Matthews S, Frauenknecht K, Leukel P, Mazur J, Poplawski A, Muellenbach R, Sommer CJ, Thal SC, and Engelhard K. 2016. Systemic PaO2 Oscillations Cause Mild Brain Injury in a Pig Model. Crit Care Med 44:e253-263. 10.1097/CCM.0000000000001399

Matute-Bello G, Frevert CW, and Martin TR. 2008. Animal models of acute lung injury. Am J Physiol Lung Cell Mol Physiol 295:L379-399. 10.1152/ajplung.00010.2008

Mikkelsen ME, Christie JD, Lanken PN, Biester RC, Thompson BT, Bellamy SL, Localio AR, Demissie E, Hopkins RO, and Angus DC. 2012. The adult respiratory distress syndrome cognitive outcomes study: long-term neuropsychological function in survivors of acute lung injury. Am J Respir Crit Care Med 185:1307-1315. 10.1164/rccm.201111-2025OC

Nieman GF, Gatto LA, and Habashi NM. 2015. Impact of mechanical ventilation on the pathophysiology of progressive acute lung injury. J Appl Physiol (1985) 119:1245-1261. 10.1152/japplphysiol.00659.2015

Pandharipande PP, Girard TD, Jackson JC, Morandi A, Thompson JL, Pun BT, Brummel NE, Hughes CG, Vasilevskis EE, Shintani AK, Moons KG, Geevarghese SK, Canonico A, Hopkins RO, Bernard GR, Dittus RS, Ely EW, and Investigators B-IS. 2013. Long-term cognitive impairment after critical illness. N Engl J Med 369:1306-1316.

10.1056/NEJMoa1301372

Peer) reviewing PDF | (2020:04:47363:2:1:NEW 7 Nov 2020) 
435

436

437

438

439

440

441

442

443

444

445

446

447

448

449

450

451

452

453

454

455

456

457

458

459

460

461

462

463

464

465

466

467

468

469

470

471

Popa-Wagner A, Mitran S, Sivanesan S, Chang E, and Buga AM. 2013. ROS and brain diseases: the good, the bad, and the ugly. Oxid Med Cell Longev 2013:963520. $10.1155 / 2013 / 963520$

Rezoagli E, Fumagalli R, and Bellani G. 2017. Definition and epidemiology of acute respiratory distress syndrome. Ann Trans/ Med 5:282. 10.21037/atm.2017.06.62

Rochfort KD, and Cummins PM. 2015. The blood-brain barrier endothelium: a target for proinflammatory cytokines. Biochem Soc Trans 43:702-706. 10.1042/BST20140319

Ruiz-Valdepenas L, Martinez-Orgado JA, Benito C, Millan A, Tolon RM, and Romero J. 2011. Cannabidiol reduces lipopolysaccharide-induced vascular changes and inflammation in the mouse brain: an intravital microscopy study. J Neuroinflammation 8:5. 10.1186/17422094-8-5

Semmler A, Frisch C, Debeir T, Ramanathan M, Okulla T, Klockgether T, and Heneka MT. 2007. Long-term cognitive impairment, neuronal loss and reduced cortical cholinergic innervation after recovery from sepsis in a rodent model. Exp Neurol 204:733-740. 10.1016/j.expneurol.2007.01.003

Semmler A, Okulla T, Sastre M, Dumitrescu-Ozimek L, and Heneka MT. 2005. Systemic inflammation induces apoptosis with variable vulnerability of different brain regions. $J$ Chem Neuroanat 30:144-157. 10.1016/j.jchemneu.2005.07.003

Songarj P, Luh C, Staib-Lasarzik I, Engelhard K, Moosmann B, and Thal SC. 2015. The antioxidative, non-psychoactive tricyclic phenothiazine reduces brain damage after experimental traumatic brain injury in mice. Neurosci Lett 584:253-258. 10.1016/j.neulet.2014.10.037

Thibeault I, Laflamme N, and Rivest S. 2001. Regulation of the gene encoding the monocyte chemoattractant protein 1 (MCP-1) in the mouse and rat brain in response to circulating LPS and proinflammatory cytokines. J Comp Neurol 434:461-477.

Tsao N, Hsu HP, Wu CM, Liu CC, and Lei HY. 2001. Tumour necrosis factor-alpha causes an increase in blood-brain barrier permeability during sepsis. J Med Microbiol 50:812-821. 10.1099/0022-1317-50-9-812

Wang R, Chen J, and Wu G. 2015. Variable lung protective mechanical ventilation decreases incidence of postoperative delirium and cognitive dysfunction during open abdominal surgery. Int J Clin Exp Med 8:21208-21214.

Wes PD, Sayed FA, Bard F, and Gan L. 2016. Targeting microglia for the treatment of Alzheimer's Disease. Glia 64:1710-1732. 10.1002/glia.22988

Ziebart A, Hartmann EK, Thomas R, Liu T, Duenges B, Schad A, Bodenstein M, Thal SC, and David M. 2014. Low tidal volume pressure support versus controlled ventilation in early experimental sepsis in pigs. Respir Res 15:101. 10.1186/s12931-014-0101-6

Peer) reviewing PDF | (2020:04:47363:2:1:NEW 7 Nov 2020) 


\section{Table $\mathbf{1}$ (on next page)}

PEEP/FiO ${ }_{2}$-setting in this experimental study 
1

\begin{tabular}{|l|l|l|l|l|l|l|l|l|}
\hline $\mathrm{FiO}_{2}$ & 0.4 & 0.4 & 0.5 & 0.5 & 0.6 & 0.7 & 0.7 & 0.7 \\
\hline PEEP & 5 & 8 & 8 & 10 & 10 & 10 & 12 & 14 \\
\hline
\end{tabular}

2

3

\begin{tabular}{|l|l|l|l|l|l|l|l|l|}
\hline $\mathrm{FiO}_{2}$ & 0.8 & 0.9 & 0.9 & 0.9 & 1.0 & 1.0 & 1.0 & 1.0 \\
\hline PEEP & 14 & 14 & 16 & 18 & 18 & 20 & 22 & 24 \\
\hline
\end{tabular}




\section{Table 2 (on next page)}

\section{Pulmonal parameters}

Data shown as mean values and standard deviation

Abbreviations: et $\mathrm{CO}_{2}=$ endtidal $\mathrm{CO}_{2} \mathrm{EVLWI}=$ extravascular lung water index $\mathrm{FiO}_{2}=$ inspiratory fraction of $\mathrm{O}_{2}$ PEEP $=$ positive endexpiratory pressure $P_{\text {Peak }}=$ peak pressure $V_{t}=$ tidal volume 


\begin{tabular}{|c|c|c|c|c|}
\hline & & CTR & OAI & p-value \\
\hline \multirow{5}{*}{$\begin{array}{l}\text { PEEP } \\
\left(\mathrm{cm} \mathrm{H} \mathrm{H}_{2} \mathrm{O}\right)\end{array}$} & BLH & $4 \pm 0$ & $4 \pm 0$ & n.s. \\
\hline & $\mathbf{0 h}$ & $4 \pm 0$ & $6 \pm 2$ & 0.043 \\
\hline & $6 h$ & $4 \pm 0$ & $9 \pm 2$ & $<0.001$ \\
\hline & $12 \mathrm{~h}$ & $4 \pm 0$ & $7 \pm 3$ & $<\mathbf{0 . 0 0 1}$ \\
\hline & $18 \mathrm{~h}$ & $4 \pm 0$ & $7 \pm 3$ & 0.002 \\
\hline \multirow{5}{*}{$\begin{array}{l}\mathbf{P}_{\text {peak }} \\
\left(\mathrm{cm} \mathrm{H} \mathrm{H}_{2} \mathrm{O}\right)\end{array}$} & BLH & $15 \pm 2$ & $16 \pm 3$ & n.s. \\
\hline & $\mathbf{0 h}$ & $14 \pm 1$ & $28 \pm 6$ & $<0.001$ \\
\hline & $6 h$ & $15 \pm 2$ & $28 \pm 3$ & $<0.001$ \\
\hline & $12 \mathrm{~h}$ & $16 \pm 2$ & $28 \pm 6$ & $<0.001$ \\
\hline & $18 h$ & $17 \pm 2$ & $30 \pm 5$ & $<0.001$ \\
\hline \multirow{5}{*}{$\begin{array}{l}\mathbf{V}_{\mathbf{T}} \\
(\mathrm{ml} / \mathrm{kg})\end{array}$} & BLH & $6 \pm 0$ & $6 \pm 1$ & n.s. \\
\hline & $\mathbf{0 h}$ & $6 \pm 0$ & $7 \pm 1$ & n.s. \\
\hline & $6 h$ & $6 \pm 0$ & $7 \pm 1$ & n.s. \\
\hline & $12 \mathrm{~h}$ & $6 \pm 0$ & $6 \pm 1$ & n.s. \\
\hline & $18 \mathrm{~h}$ & $6 \pm 0$ & $6 \pm 1$ & n.s. \\
\hline \multirow{5}{*}{$\begin{array}{l}\mathbf{e t C O}_{2} \\
(\mathrm{mmHg})\end{array}$} & BLH & 39+3 & $38 \pm 4$ & n.s. \\
\hline & $\mathbf{0 h}$ & $36 \pm 2$ & $37 \pm 4$ & n.s. \\
\hline & $6 h$ & $37 \pm 4$ & $39 \pm 3$ & n.s. \\
\hline & $12 \mathrm{~h}$ & $37 \pm 2$ & $39 \pm 3$ & n.s. \\
\hline & $18 \mathrm{~h}$ & $36 \pm 2$ & $39 \pm 4$ & n.s. \\
\hline \multirow{5}{*}{$\begin{array}{l}\mathrm{FiO}_{2} \\
(\%)\end{array}$} & BLH & $40 \pm 0$ & $40 \pm 0$ & n.s. \\
\hline & $\mathbf{0 h}$ & $100 \pm 0$ & $100 \pm 0$ & n.s. \\
\hline & $6 h$ & $40 \pm 0$ & $55 \pm 10$ & $<0.001$ \\
\hline & $12 \mathrm{~h}$ & $39 \pm 4$ & $48 \pm 10$ & 0.005 \\
\hline & $18 \mathrm{~h}$ & $40 \pm 0$ & $45 \pm 10$ & n.s. \\
\hline \multirow{5}{*}{$\begin{array}{l}\text { EVLWI } \\
(\mathrm{ml} / \mathrm{kg})\end{array}$} & BLH & $11 \pm 1$ & $10 \pm 2$ & n.s. \\
\hline & $\mathbf{0 h}$ & $12 \pm 1$ & $19 \pm 4$ & 0.003 \\
\hline & $6 h$ & $12 \pm 2$ & $21 \pm 7$ & $<0.001$ \\
\hline & $12 \mathrm{~h}$ & $14 \pm 2$ & $17 \pm 6$ & n.s. \\
\hline & $18 \mathrm{~h}$ & $14 \pm 3$ & $17 \pm 5$ & n.s. \\
\hline
\end{tabular}




\begin{tabular}{ll|ll|l|} 
Oxygenation & BLH & $503 \pm 65$ & $496 \pm 58$ & n.s. \\
Ratio & 0h & $544 \pm 66$ & $101 \pm 28$ & $<0.001$ \\
$(\mathrm{mmHg})$ & $6 \mathrm{~h}$ & $452 \pm 55$ & $188 \pm 70$ & $<0.001$ \\
& $12 \mathrm{~h}$ & $453 \pm 73$ & $221 \pm 48$ & $<0.001$ \\
& $18 \mathrm{~h}$ & $400 \pm 59$ & $216 \pm 50$ & $<0.001$ \\
\hline Wet-to-dry & & $5 \pm 0$ & $6 \pm 1$ & 0.08 \\
Ratio & & & & \\
\hline
\end{tabular}

1 


\section{Table 3(on next page)}

\section{Cardiovascular parameters.}

Data shown as mean values and standard deviation.

Abbreviations: $\mathrm{Cl}=$ cardiac index $\mathrm{CVP}=$ central venous pressure $\mathrm{HR}=$ heart rate $\mathrm{MAP}=$ mean arterial pressure MPAP = mean pulmonary arterial pressure PCWP $=$ pulmonary capillary wedge pressure 


\begin{tabular}{|c|c|c|c|c|}
\hline & & CTR & OAI & p-value \\
\hline \multirow{5}{*}{$\begin{array}{l}\text { HR } \\
\left(\min ^{-1}\right)\end{array}$} & BLH & $77 \pm 10$ & $77 \pm 15$ & n.s. \\
\hline & $\mathbf{0 h}$ & $72 \pm 9$ & $124 \pm 32$ & $<0.001$ \\
\hline & $6 h$ & $76 \pm 15$ & $119 \pm 40$ & 0.004 \\
\hline & $12 \mathrm{~h}$ & $75 \pm 18$ & $117 \pm 39$ & 0.005 \\
\hline & $18 h$ & $68+8$ & $112+44$ & 0.003 \\
\hline \multirow{5}{*}{$\begin{array}{l}\text { MAP } \\
(\mathrm{mmHg})\end{array}$} & BLH & $72 \pm 5$ & $75 \pm 11$ & n.s. \\
\hline & $\mathbf{0 h}$ & $76 \pm 8$ & $73 \pm 6$ & n.s. \\
\hline & $6 h$ & $74 \pm 8$ & $67 \pm 8$ & n.s. \\
\hline & $12 \mathrm{~h}$ & $71 \pm 12$ & $69 \pm 6$ & n.s. \\
\hline & $18 h$ & $68 \pm 8$ & $67 \pm 7$ & n.s. \\
\hline \multirow{5}{*}{$\begin{array}{l}\text { MPAP } \\
(\mathrm{mmHg})\end{array}$} & BLH & $13 \pm 4$ & $16 \pm 3$ & n.s. \\
\hline & $\mathbf{0 h}$ & $12 \pm 3$ & $38 \pm 4$ & $<0.001$ \\
\hline & $6 h$ & $14+4$ & $30 \pm 5$ & $<0.001$ \\
\hline & $12 \mathrm{~h}$ & $16 \pm 2$ & $27 \pm 4$ & $<0.001$ \\
\hline & $18 \mathrm{~h}$ & $15 \pm 2$ & $27 \pm 2$ & $<0.001$ \\
\hline \multirow{5}{*}{$\begin{array}{l}\text { CVP } \\
(\mathrm{mmHg})\end{array}$} & BLH & $6 \pm 2$ & $6 \pm 3$ & n.s. \\
\hline & $\mathbf{O h}$ & $6 \pm 3$ & $7 \pm 4$ & n.s. \\
\hline & $6 h$ & $8 \pm 4$ & $8 \pm 3$ & n.s. \\
\hline & $12 \mathrm{~h}$ & $6 \pm 2$ & $9 \pm 3$ & n.s. \\
\hline & $18 \mathrm{~h}$ & $6 \pm 1$ & $10 \pm 3$ & n.s. \\
\hline \multirow{5}{*}{$\begin{array}{l}\mathbf{P C W P} \\
(\mathrm{mmHg})\end{array}$} & BLH & $7 \pm 1$ & $8 \pm 1$ & n.s. \\
\hline & $\mathbf{O h}$ & $7 \pm 2$ & $9 \pm 2$ & n.s. \\
\hline & $6 h$ & $7 \pm 1$ & $8 \pm 2$ & n.s. \\
\hline & $12 \mathrm{~h}$ & $7 \pm 2$ & $9 \pm 2$ & n.s. \\
\hline & $18 h$ & $7 \pm 2$ & $10 \pm 1$ & n.s. \\
\hline \multirow{5}{*}{$\begin{array}{l}\mathbf{C I} \\
\left(1 / \mathrm{min} / \mathrm{m}^{2}\right)\end{array}$} & BLH & $3.41 \pm 0.43$ & $3.34 \pm 0.85$ & n.s. \\
\hline & $\mathbf{0 h}$ & $3.26 \pm 0.43$ & $3.87 \pm 0.75$ & n.s. \\
\hline & $6 h$ & $3.40 \pm 0.68$ & $3.87 \pm 0.92$ & n.s. \\
\hline & $12 \mathrm{~h}$ & $3.61 \pm 0.61$ & $4.44 \pm 1.41$ & n.s. \\
\hline & $18 \mathrm{~h}$ & $3.28 \pm 0.34$ & $4.83 \pm 1.39$ & 0.002 \\
\hline
\end{tabular}




\begin{tabular}{ll|ll|l|} 
Norepinephrine & BLH & $\mathbf{0 . 0 4} \pm \mathbf{0 . 1 1}$ & $\mathbf{0 . 0 0} \pm \mathbf{0}$ & n.s. \\
$(\mu \mathrm{g} / \mathrm{kg} / \mathrm{min})$ & $0 \mathrm{~h}$ & $\mathbf{0 . 0 0 \pm 0}$ & $\mathbf{0 . 5 5} \pm \mathbf{0 . 6 1}$ & n.s. \\
& $6 \mathrm{~h}$ & $\mathbf{0 . 0 1 \pm 0 . 0 4}$ & $\mathbf{0 . 5 8} \pm \mathbf{1 . 1 3}$ & n.s. \\
& $12 \mathrm{~h}$ & $\mathbf{0 . 0 3} \pm \mathbf{0 . 0 5}$ & $\mathbf{0 . 6 6} \pm \mathbf{1 . 0 2}$ & n.s. \\
& $18 \mathrm{~h}$ & $\mathbf{0 . 0 1} \pm \mathbf{0 . 0 4}$ & $\mathbf{1 . 0 9 \pm 1 . 4 4}$ & $\mathbf{0 . 0 0 7}$ \\
\hline
\end{tabular}

1

2

3 


\section{Figure 1}

Brain histology - neurons.

A Mean number of HE-stained neurons in Gyurs dentatus, CA1, CA2, CA3 and CA4 of the Hippocampus.

B Proportion of apoptotic neurons in Gyurs dentatus, CA1, CA3 and CA4 of the Hippocampus. 


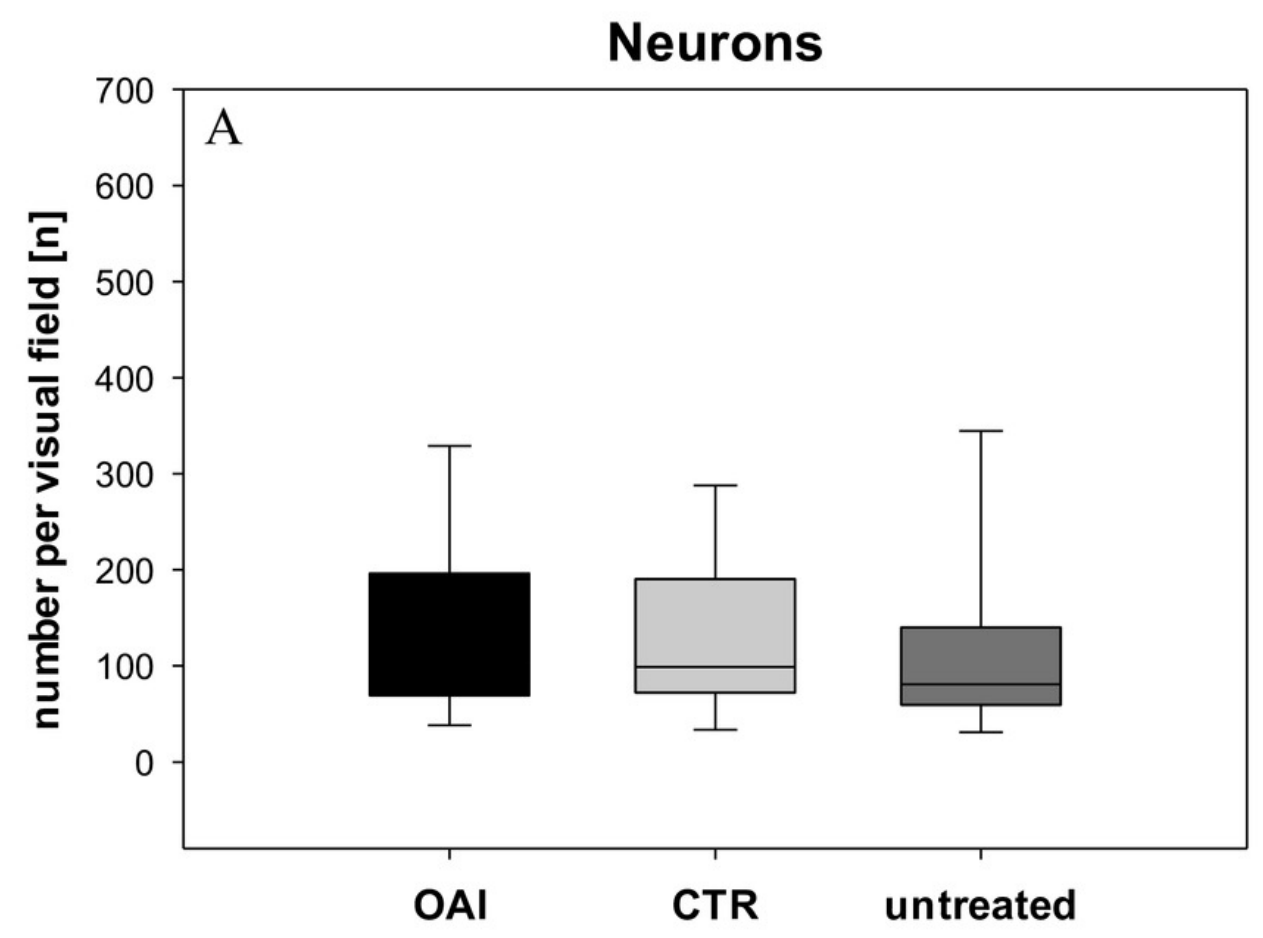

\section{Proportion of apoptotic Neurons}

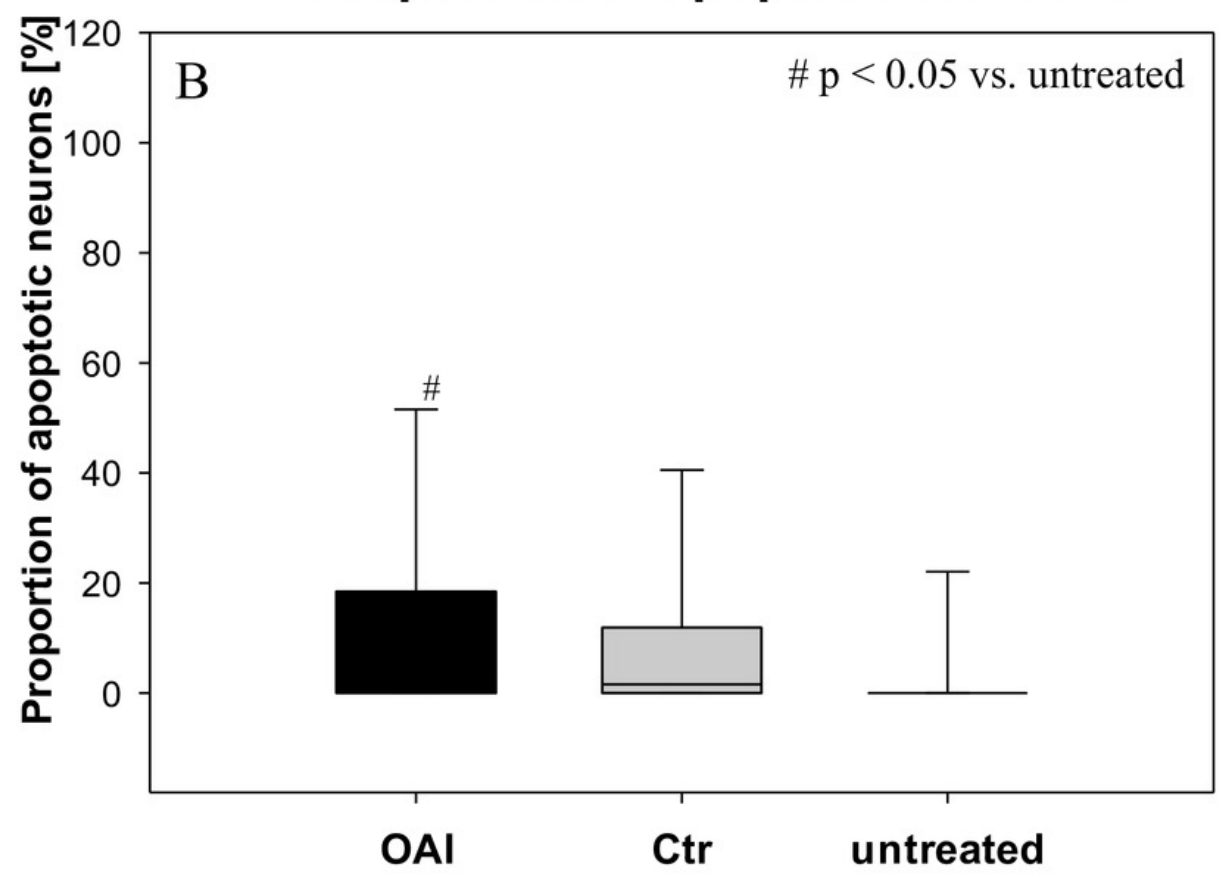


Figure 2

Brain histology - microglia cells.

A Mean number of Iba-1 stained microglia cells in Gyurs dentatus, CA1, CA2, CA3 and CA4 of the Hippocampus.

B Mean number of active microglia cells in Gyurs dentatus, CA1, CA3 and CA4 of the Hippocampus. 


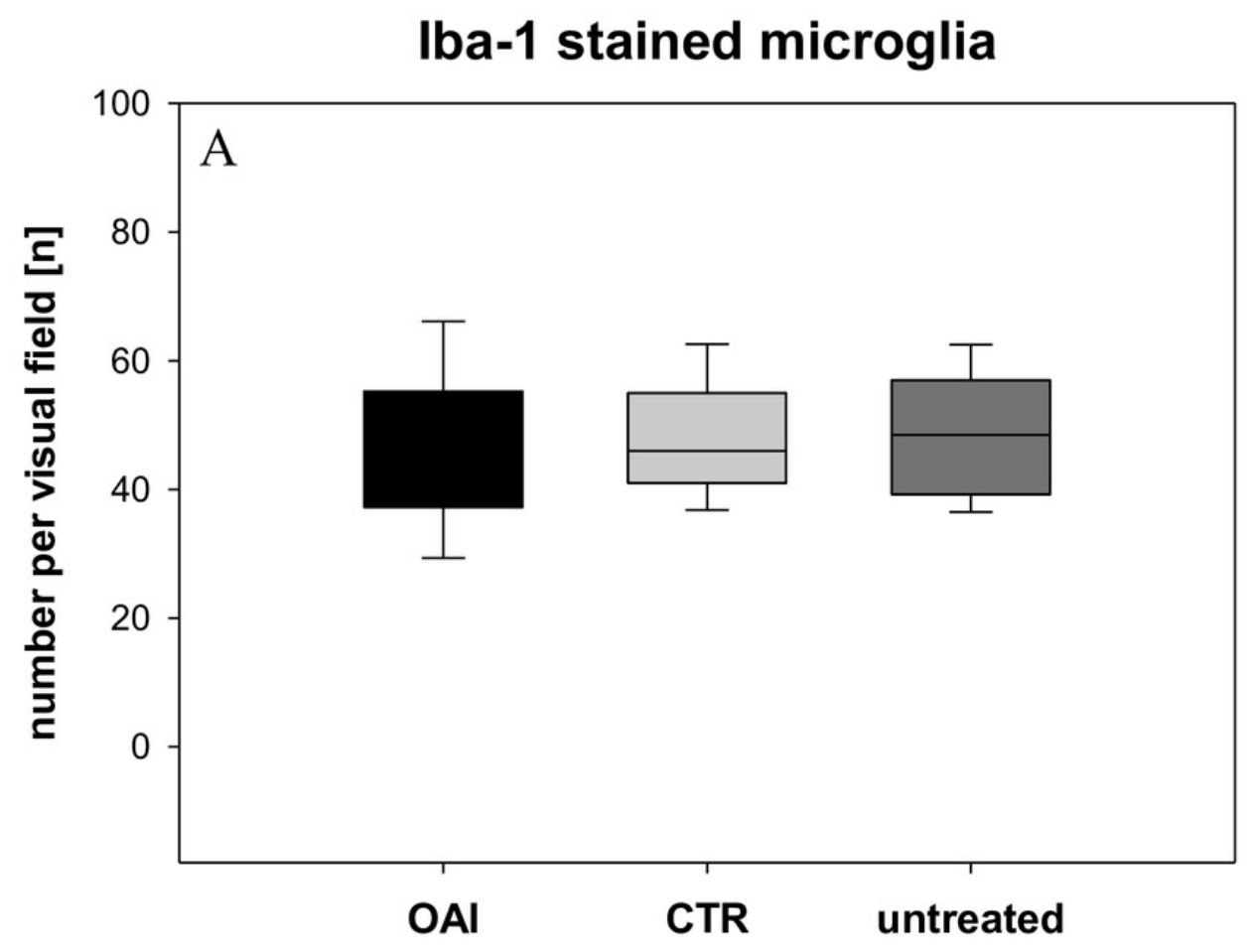

Active microglia cells

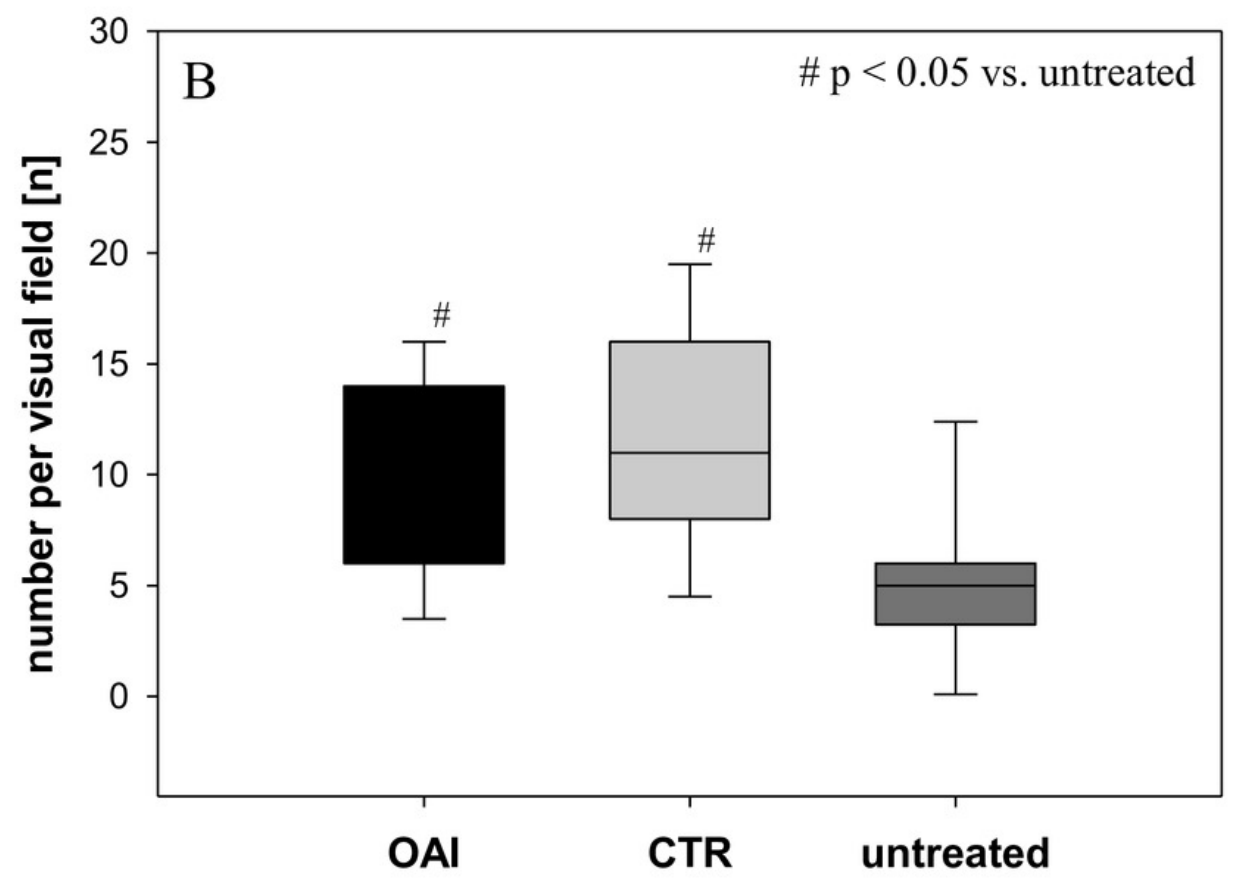




\section{Figure 3}

Lung injury score.

In HE-stained lung slices 7 different parameters (overdistension, epithelial destruction, inflammatory infiltration, alveolar edema, hemorrhage, interstitial edema, and microatelectasis) were evaluated with a maximum score of 175 points. 


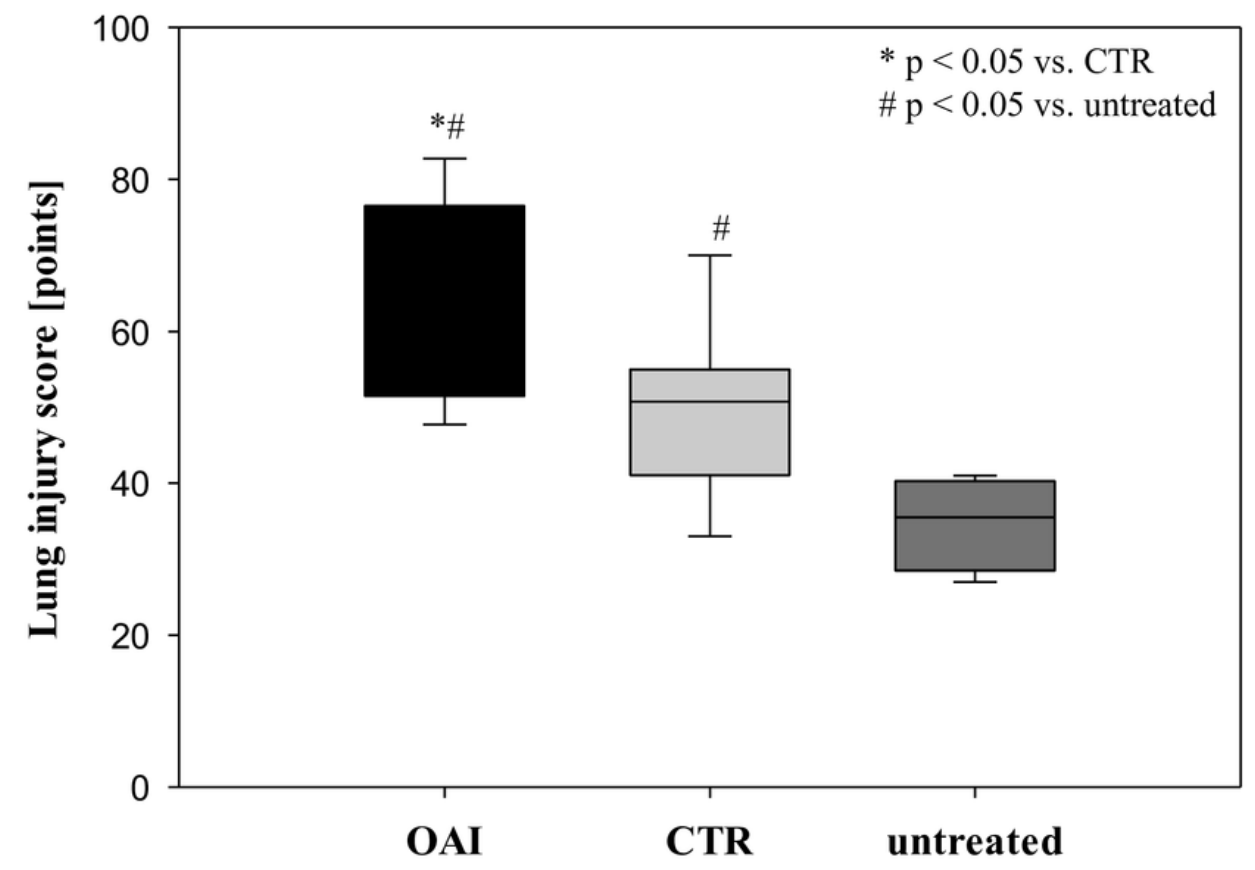




\section{Figure 4}

\section{Cerebral levels of TNFalpha mRNA.}

A Number of TNFalpha mRNA-copies normalized to PPIA in the cortex.

B Number of TNFalpha mRNA-copies normalized to PPIA in the hippocampus. 

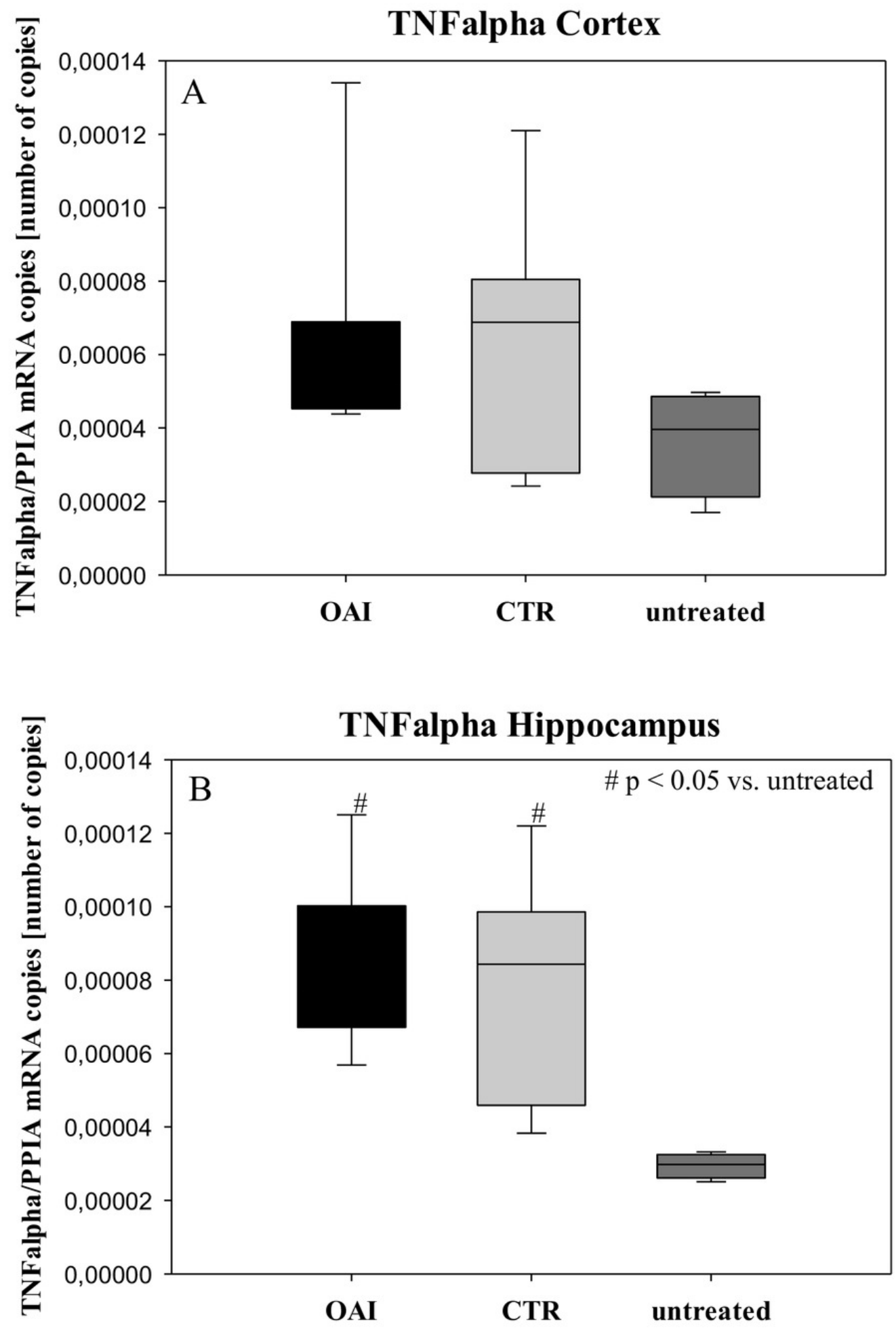


\section{Figure 5}

\section{Cerebral levels of IL-6 mRNA.}

A Number of IL-6 mRNA-copies normalized to PPIA in the cortex.

B Number of IL-6 mRNA-copies normalized to PPIA in the hippocampus. 

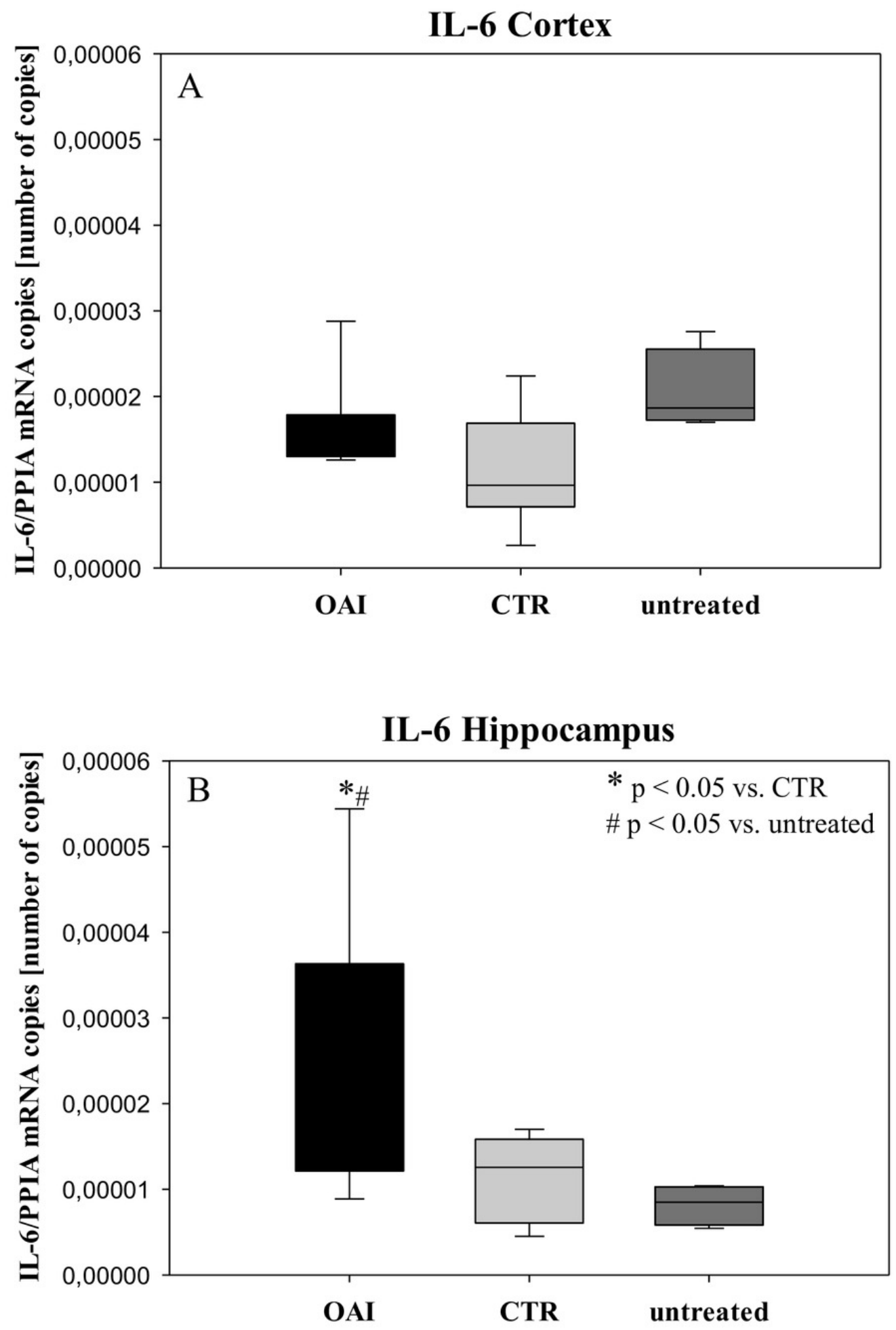
Figure 6

\section{Cerebral levels of IL-8 mRNA.}

A Number of IL-8 mRNA-copies normalized to PPIA in the cortex.

B Number of IL-8 mRNA-copies normalized to PPIA in the hippocampus. 


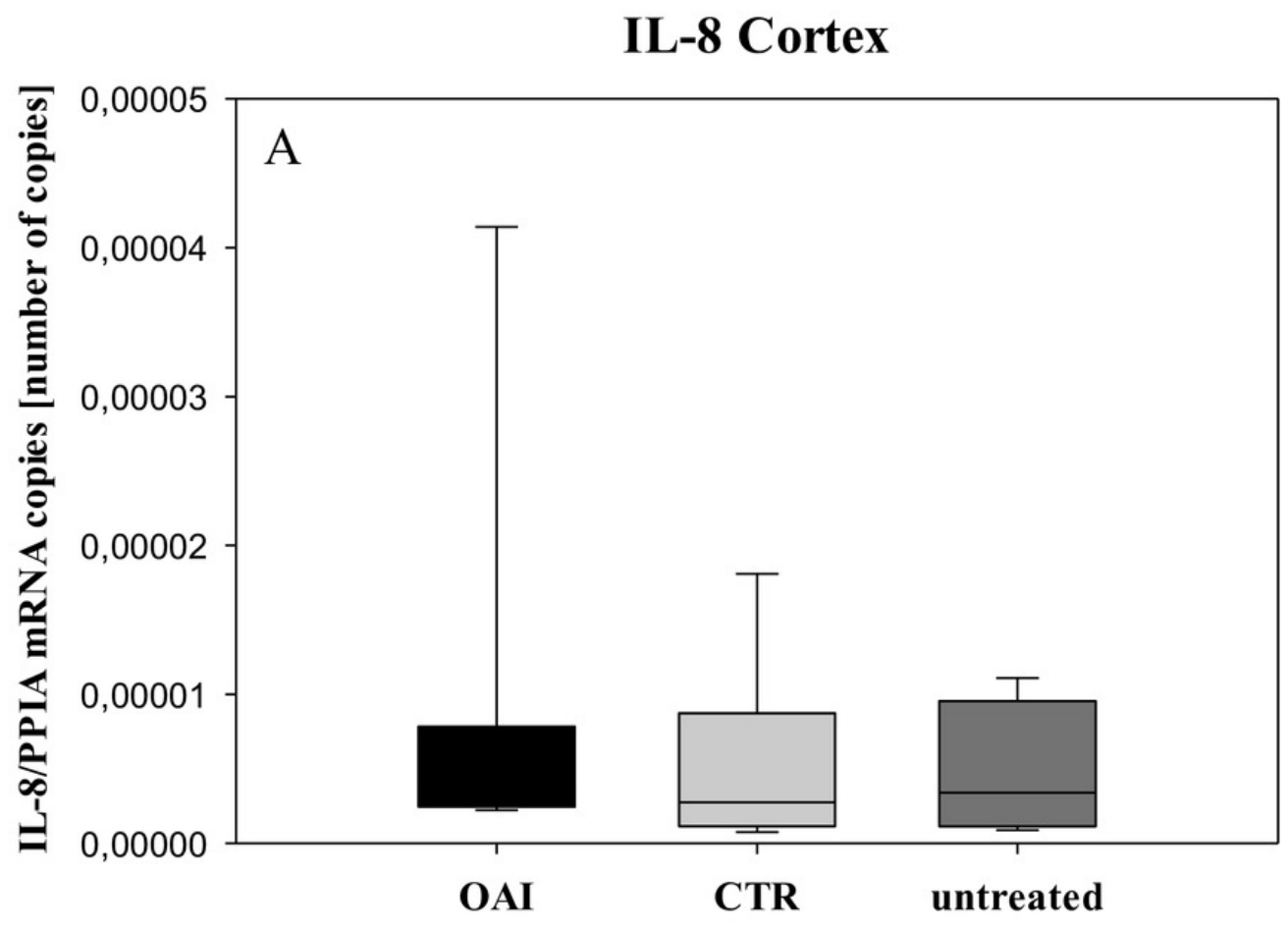

\section{IL-8 Hippocampus}

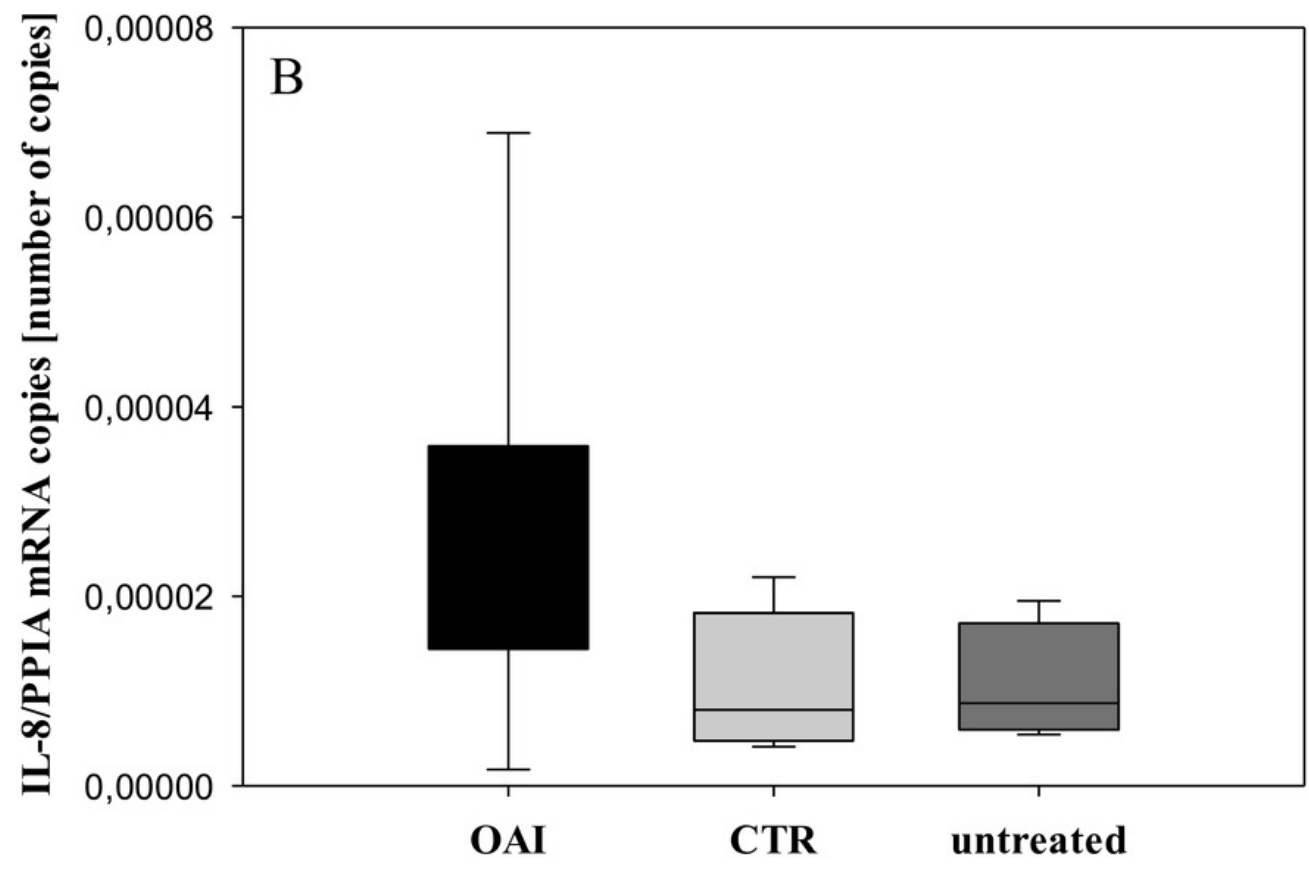


Figure 7

Cerebral levels of IL-1beta mRNA.

A Number of IL-1beta mRNA-copies normalized to PPIA in the cortex. B Number of IL-1beta mRNA-copies normalized to PPIA in the hippocampus. 

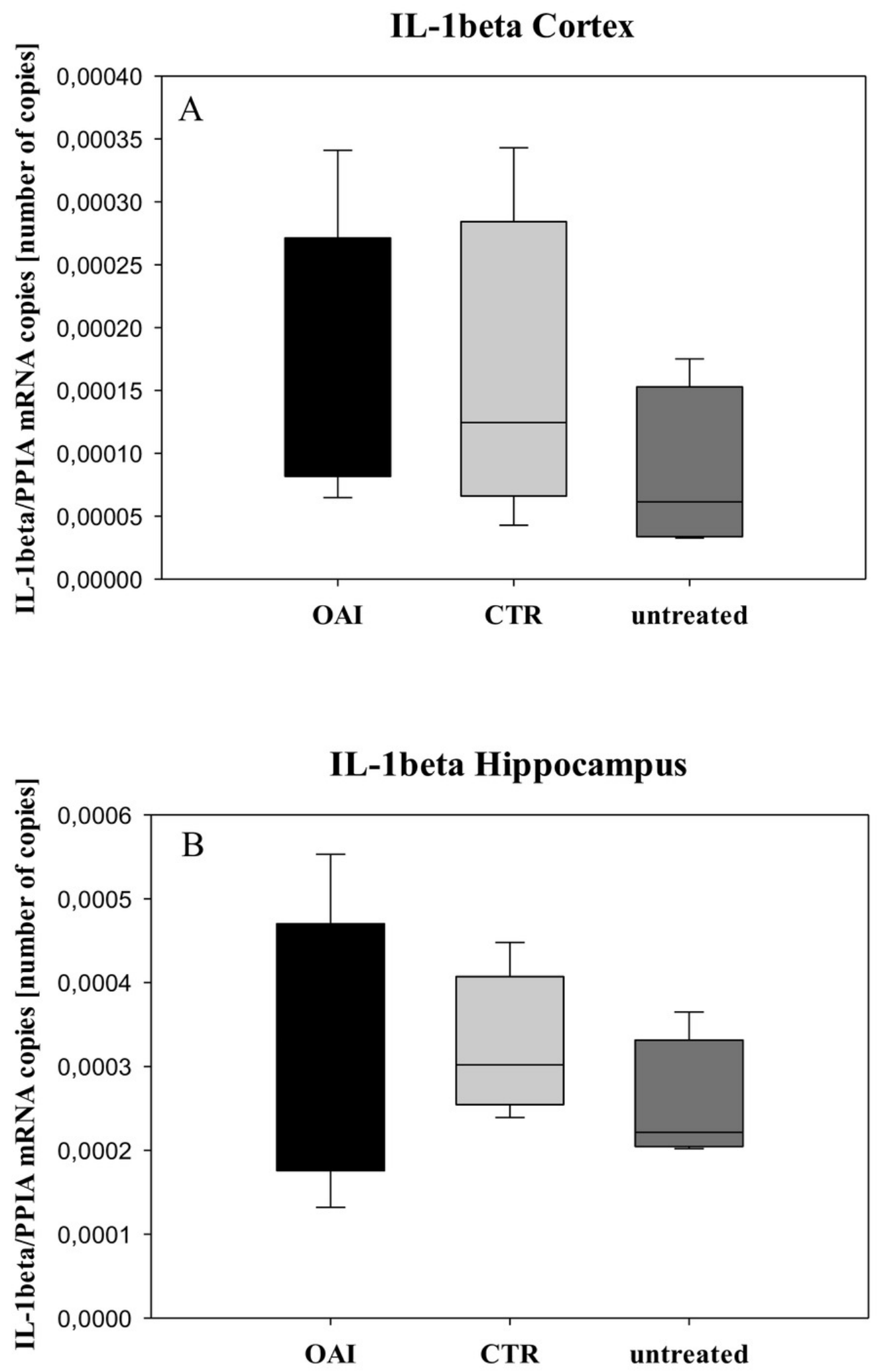
Figure 8

Time course of plasma cytokines after induction of ARDS.
A Plasma levels of TNFalpha over time.
B Plasma levels of IL-6 over time. 


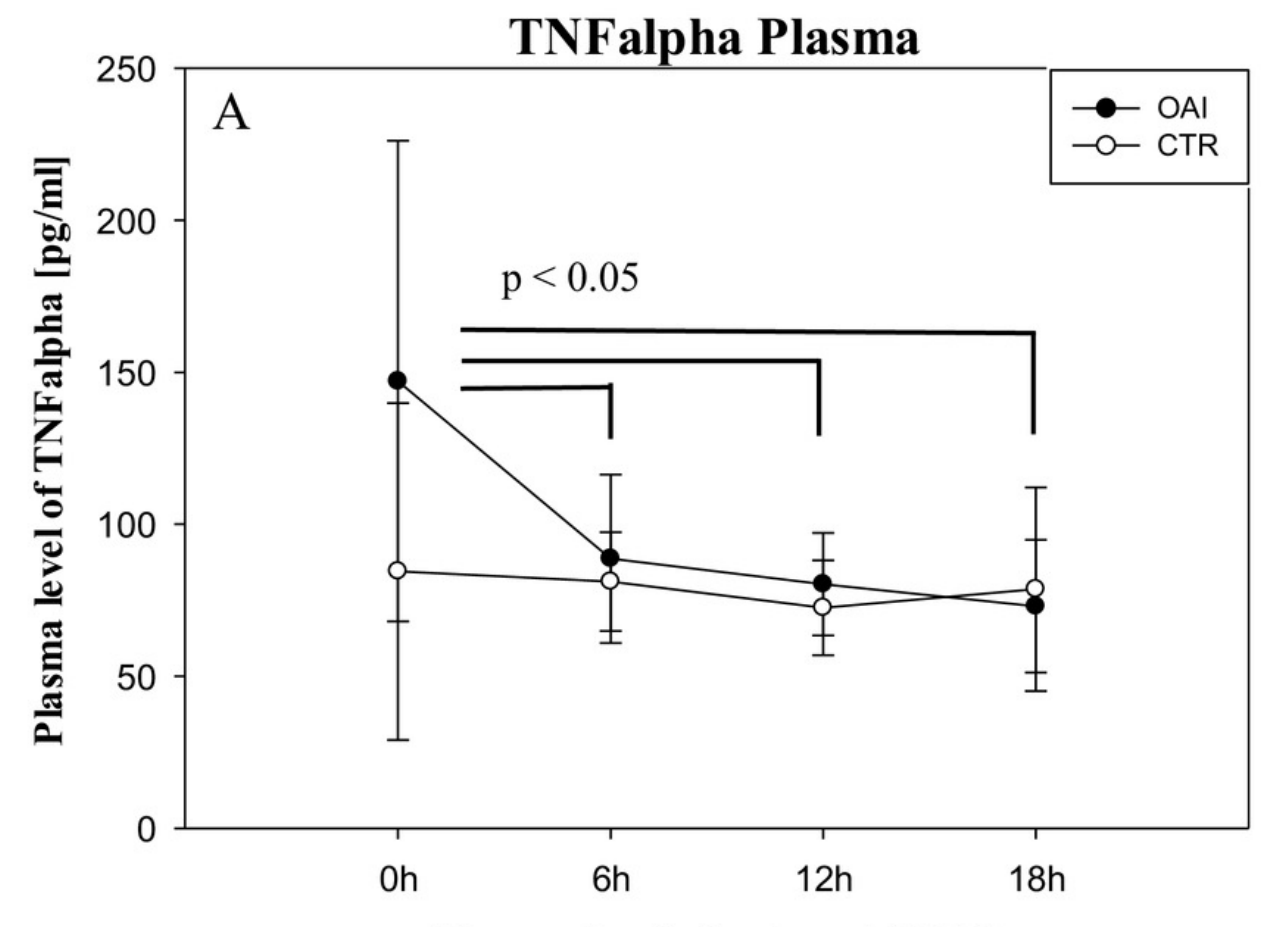

Hours after induction of ARDS

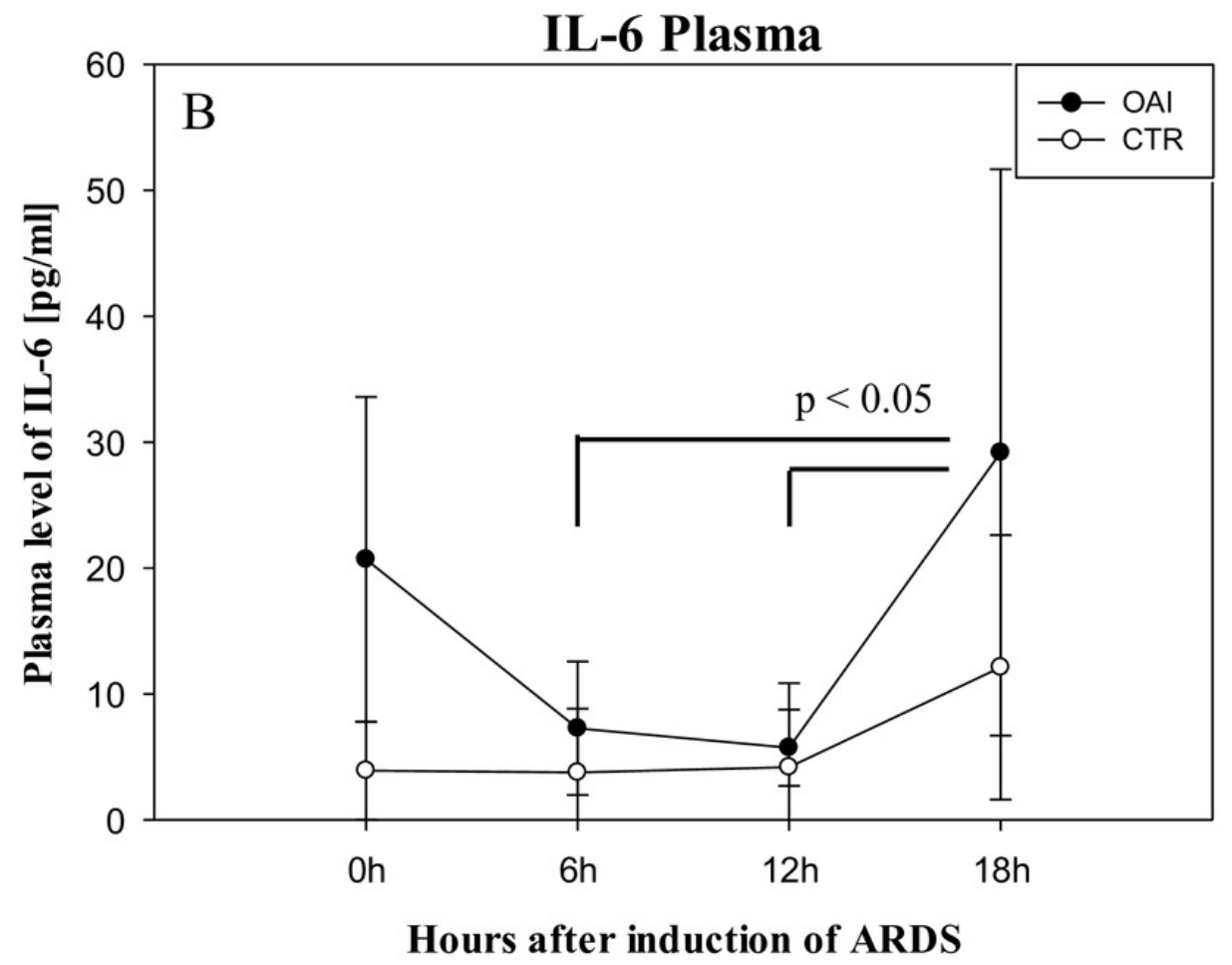

